\title{
Poly(ethyleneglycol) column for the determination of acetaminophen, phenylephrine and chlorpheniramine in pharmaceutical formulations
}

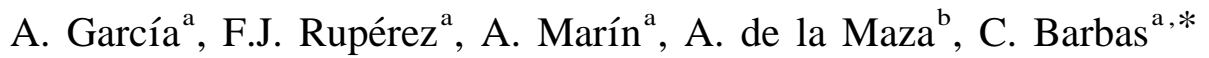 \\ a Facultad de CC Experimentales y de la Salud. Universidad S. Pablo-CEU Urbanización Montepríncipe, Ctra. Boadilla del Monte, \\ km 5,3-28668 Madrid, Spain \\ ${ }^{\mathrm{b}}$ Laboratorios CINFA S.A., Polígono Areta. Huarte, Pamplona, Spain
}

Received 6 May 2002; received in revised form 11 October 2002; accepted 29 October 2002

\begin{abstract}
New polar reversed-phase stationary phases in HPLC provide specific selectivities which can help to solve traditional chromatographic problems related to the development of chromatographic methods with widely different retention times for the sample components. One such case is the analysis of pharmaceutical formulations against the common cold. Acetaminophen, phenylephrine and chlorpheniramine, compounds with different polarities, are frequently associated in these drugs. An isocratic and rapid HPLC method for the simultaneous determination of the three compounds, acetaminophen, phenylephrine and chlorpheniramine, in capsules as pharmaceutical formulations, including the separation of impurities (4-aminophenol and 4-chloracetanilide) and excipients, has been developed and validated. The final chromatographic conditions employed a Supelco Discovery HS PEG column poly(ethyleneglycol) $15 \times 0.46 \mathrm{~cm}, 5 \mu \mathrm{m}$. The mobile phase was $20 \mathrm{~m} M$ phosphate buffer, $\mathrm{pH} 7.0$-acetonitrile $(90: 10, \mathrm{v} / \mathrm{v})$ at a flow-rate of $1 \mathrm{ml} / \mathrm{min}$. UV detection was performed at 215 $\mathrm{nm}$ for all the compounds except acetaminophen, which was measured at $310 \mathrm{~nm}$. Validation parameters permit us to consider this method suitable.
\end{abstract}

(C) 2002 Elsevier Science B.V. All rights reserved.

Keywords: Acetaminophen; Phenylephrine; Chlorpheniramine

\section{Introduction}

In recent years, novel LC stationary phases with enhanced selectivity are providing new tools to solve classical problems in pharmaceutical analysis. One of these problems is the analysis of pharmaceutical formulations against the common cold. These preparations usually contain active compounds against

*Corresponding author. Fax: +34-91-351-0475.

E-mail address: cbarbas@ceu.es (C. Barbas). different symptoms which have very different polarities and, therefore, chromatographic behaviour. A common combination contains acetaminophen (paracetamol), which is analgesic and antipiretic as the main component and small amounts of phenylephrine, which is sympathomimetic (decongestants) and chlorpheniramine maleate, which is an $\mathrm{H}_{1}$-receptor antagonist (antihistaminic). The chemical structures and characteristics of these compounds can be found in Table 1 .

Their determination is further complicated by the 
Table 1

Chemical structures of the assayed compounds

\begin{tabular}{|c|c|c|c|c|c|}
\hline NAME & $\begin{array}{l}\text { MOLECULAR } \\
\text { FORM }\end{array}$ & $\begin{array}{c}\text { ESTRUCTURAL } \\
\text { FORM }\end{array}$ & $\begin{array}{l}\text { MOLECULAR } \\
\text { WEIGHT }\end{array}$ & pKa & REF. \\
\hline Acetaminophen & $\mathrm{C}_{8} \mathrm{H}_{9} \mathrm{NO}_{2}$ & & 151.17 & 9.5 & [26] \\
\hline Phenylephrine & $\mathrm{C}_{9} \mathrm{H}_{13} \mathrm{NO}_{2}$ & & 167.21 & $8.9 / 10.1$ & {$[27]$} \\
\hline Chlorpheniramine & $\mathrm{C}_{16} \mathrm{H}_{19} \mathrm{ClN}_{2}$ & & 274.80 & 9.1 & {$[28,29]$} \\
\hline 4-Aminophenol & $\mathrm{C}_{6} \mathrm{H}_{7} \mathrm{NO}$ & & 109.13 & 10.46 & [30] \\
\hline Chloracetanilide & $\mathrm{C}_{8} \mathrm{H}_{8} \mathrm{CINO}$ & & 169.61 & & \\
\hline
\end{tabular}

presence of impurities such as 4-aminophenol and 4-chloroacetanilide related to acetaminophen. The dosage forms also contain excipients. In a previous work [1] we carried out a detailed review of the analytical methods published for measuring some of these substances, alone or in different combinations. Phenylpropanolamine hydrochloride and acetaminophen have been determined in pharmaceutical preparations by Raman spectroscopy [2]; phenylpropanolamine and chlorpheniramine together with other active compounds have been measured by GC [3-5] and by HPLC [6]. Different analgesics including acetaminophen and chlorpheniramine have been analysed by HPLC with on-line postcolumn photochemical derivatization [7] and by GC [8]. Acetaminophen and chlorpheniramine in human plasma have been determined by LC-MS-MS and by HPLC in combination with codeine [9] and pheudoephedrine $[10,11]$. Acetaminophen, phenylpropanolamine, chlorpheniramine and dextromethorphan were separated by MECC $[12,13]$ in cold medicines. Acetaminophen and chlorpheniramine have been determined by EKC employing bile salts in cold medicines [14].

Three methods in the literature report the quantitation of acetaminophen, chlorpheniramine and phenylpropanolamine. The method of Gupta et al.
[15] requires three different analysis with three different mobile phases. Indrayanto et al. [16] and Zhao et al. [17] developed a simultaneous assay of the three active compounds by HPLC. Krieger et al. developed a method for the separation of acetaminophen in analgesic preparations containing chlorpheniramine maleate, phenylephrine hydrochloride, and other active components by HPLC [18] but the method did not permit the separation of the impurities, although many modifications were tested. Some of the methods developed by column suppliers for several standards have also been included [1923]. However, none of the methods separates the three actives here proposed, and the impurities. In a previous work we developed and validated a HPLC method for the simultaneous determination of acetaminophen, phenylephrine and chlorpheniramine in pharmaceutical formulations such as capsules and sachets, including the separation of impurities and excipients with a gradient elution in a SymmetryShield RP8. The run lasted $20 \mathrm{~min}$. The method has been employed for stability assays, but it presents problems related to gradient elution. The change in solvent composition cause baseline shifts because of the change in optical properties of the eluent, which causes trouble at low wavelengths. Moreover, it also generates the irregular elution of 
unknown retained compounds, usually coming from water, when the organic solvent proportion increases, which complicates the impurities analysis.

During recent years, manufacturers have developed reversed-phase media suitable for analysing these types of samples. Reversed-phase media that use polar groups can yield more efficient analysis of samples that contain a wide range of polarities by reducing analysis times and avoiding gradient elution. Therefore, the objective of the present work was the development and validation, following ICH guidelines [24] of an isocratic and rapid HPLC method for the determination of acetaminophen, chlorpheniramine and phenylephrine and related impurities in capsules as pharmaceutical form, easy to be used in routine analysis both for quality and stability control.

\section{Experimental}

\subsection{Apparatus}

An Agilent technologies 1100 series (Las Rozas, Madrid, Spain) provided with an automatic injector, a diode-array detection system and a column oven was used. The chromatographic analyses were performed on a $15 \times 0.46 \mathrm{~cm}, 5 \mu \mathrm{m}$, Discovery HS PEG poly(ethyleneglycol) column (Supelco, Alcobendas, Madrid, Spain) kept at $35^{\circ} \mathrm{C}$.

Final chromatographic conditions were an isocratic elution with $20 \mathrm{~m} M$ phosphate buffer, $\mathrm{pH}$ 7.0-acetonitrile $(90: 10, \mathrm{v} / \mathrm{v})$. The phosphate buffer was prepared from $\mathrm{H}_{3} \mathrm{PO}_{4}$ by adding $\mathrm{NaOH}$ to reach $\mathrm{pH}$ 7.0. The flow-rate was $1 \mathrm{ml} / \mathrm{min}$ and the injection volume was $5 \mu \mathrm{l}$. UV detection was performed at $215 \mathrm{~nm}$ for phenylephrine and chlorpheniramine, because at this wavelength the sensitivity was higher than at other more characteristic wavelengths and it was necessary for the detection of these minor compounds. For acetaminophen $310 \mathrm{~nm}$ was employed. At this wavelength the absorbance for this compound is very low and the signal is not saturated with the large amount of acetaminophen present in the sample, and so can detect minor compounds simultaneously.

Hold up time for the chromatographic system was measured by injecting methanol as unretained compound.

\subsection{Chemicals}

Standards of actives and impurities as well as capsules, and excipients of the specialities were kindly provided by Cinfa (Pamplona, Spain). $\mathrm{NaOH}$ was from Panreac (Barcelona, Spain), and $\mathrm{H}_{3} \mathrm{PO}_{4}$ and acetonitrile from Merck (Darmstadt, Germany).

\subsection{Standard solutions and sample preparation for quantitation}

In all cases the solvent solution (SS) for standards and samples was $20 \mathrm{mM}$ phosphate buffer, $\mathrm{pH} 7.0$ acetonitrile (70:30, v/v).

A stock solution of phenylephrine was prepared with $250 \mathrm{mg}$ of phenylephrine hydrochloride exactly weighed and dissolved with SS in a $25-\mathrm{ml}$ volumetric flask. For chlorpheniramine maleate stock solution, $100 \mathrm{mg}$ were made up $25 \mathrm{ml}$ with SS. For the reference stock standard, $500 \mathrm{mg}$ of acetaminophen were weighed into a 50-ml volumetric flask and $1 \mathrm{ml}$ of phenylephrine and chlorpheniramine solutions were added. The mixture was made up to the corresponding volume with SS and treated with magnetic stirring for $10 \mathrm{~min}$.

For capsules, $610 \mathrm{mg}$ of sample (the approximate mass of one capsule) coming from a 20-capsules homogenate were dissolved in a 50-ml volumetric flask with SS. After $10 \mathrm{~min}$ of magnetic stirring an aliquot was filtered using a $0.45-\mu \mathrm{m}$ syringe filtration disk to the vials for injection into the HPLC system. In all cases three replicates were processed.

\subsection{Validation}

The selectivity refers to the extent to which a method can determine particular analytes in mixtures or matrices without interferences from other components. In this assay it was tested by running solutions containing a placebo of the formulation. Moreover, solutions of the standards with the identified impurities, 4-aminophenol and chloracetanilide, at the $1 \%$ level added were also run to show both the resolution and selectivity of the method. In all cases 
the spectra of the peaks were compared with those of the pure standards.

The linearity study verifies that the sample solutions are in a concentration range where analyte response is linearly proportional to concentration. For main component assay methods, this study is generally performed by preparing standard solutions at five concentration levels, from 75 to $125 \%$ of the target analyte concentration. In this case, acetaminophen concentrations were from 7.5 to $12.5 \mathrm{mg} / \mathrm{ml}$, phenylephrine hydrochloride from 0.15 to $0.25 \mathrm{mg} /$ $\mathrm{ml}$ and chlorpheniramine maleate from 0.06 to 0.1 $\mathrm{mg} / \mathrm{ml}$. They were prepared in 50-ml volumetric flasks by weighing the exact amount of acetaminophen (from 375.0 to $625.0 \mathrm{mg}$ ) and by adding the corresponding volumes of phenylephrine and chlorpheniramine, stock standards $(0.750-1.25 \mathrm{ml}$ each) and making up the total volume with SS. Each point was analysed three times.

The accuracy of a method is the closeness of the measured value to the true value for the sample. For pharmaceutical studies in drug products one method for determining accuracy is the application of the analytical procedure to synthetic mixtures of the drug components to which known quantities of the drug substances to be analysed have been added. It was tested in triplicate at three levels (80, 95 and 110\%) and in parallel with the linearity assay for the three main components. The percent recovery and RSD values were then calculated.

The precision of an analytical method is the amount of scatter in the results obtained from multiple analyses of an homogeneous sample. The first type is instrumental precision, which was tested by consecutively running ten injections of the same standard. Then, repeatability or intra-assay precision was tested. Intra-assay precision data were obtained by repeatedly analyzing, in one laboratory on one day, ten aliquots of a homogeneous sample, each of which was independently prepared according to the method procedure. The second type is inter-assay precision. These data were obtained by repeating the intra-assay experiment on a different day with newly prepared mobile phase and samples.

The detection limit of a method is the lowest analyte concentration that produces a response detectable above the noise level of the system, typically, three times the noise level. The detection limit needs to be determined where chromatographic peaks near the detection limit will be observed.

The quantitation limit is the lowest level of analyte that can be accurately and precisely measured. Limits of detection were calculated following IUPAC recommendations $\left[\left(a+3 S_{\mathrm{B}}\right) / b\right]$ ( $a$, the intercept; $b$, the slope; $S_{\mathrm{B}}$, the standard deviation of the blanks in the standards linearity) for chromatographic methods [25] by extrapolating to zero concentration the standards deviation of the last three points of linearity and interpolating this value in the corresponding equation.

Both quantification and detection limits are calculated by means of the study of statistical parameters of the analysis of standards in the range of $0.1 \%$ of the theoretical content of a sample, i.e. acetaminophen concentrations from 0.01 to $0.07 \mathrm{mg} / \mathrm{ml}$ phenylephrine hydrochloride from 0.0002 to 0.006 $\mathrm{mg} / \mathrm{ml}$, and chlorpheniramine maleate from 0.0001 to $0.002 \mathrm{mg} / \mathrm{ml}$.

\section{Results and discussion}

Retention and selectivity in reversed-phase HPLC result from complex combinations of hydrophobic and polar interactions among the solute, mobile phase, and stationary phase. Stationary phases have evolved from simple alkyl hydrocarbon chains to alkyl hydrocarbon chains in combination with other moieties, typically polar functional groups. These groups change retention and selectivity, particularly for solutes that have specific interactions with the polar portion of the stationary phase. So-called polar reversed phase always provide different retention and selectivity compared to $\mathrm{C}_{18}$ and frequently provide valuable improvements in separation.

A PEG phase has ether groups that can attract other polar analytes. PEG provides a very different separation of phenols compared to $\mathrm{C}_{18}$ - greater retention of some phenols (phenylephrine, acetaminophen, 4-aminophenol) that are poorly retained on $\mathrm{C}_{18}$ and faster analysis, including the elution of chlorpheniramine that eluted late on $\mathrm{C}_{18}$.

During the optimization of the method the percentage of acetonitrile was varied from 30 to $5 \%$ with the same aqueous buffer at $\mathrm{pH}$ 7.0. Phenylephrine was not affected by the variation, 4-amino- 


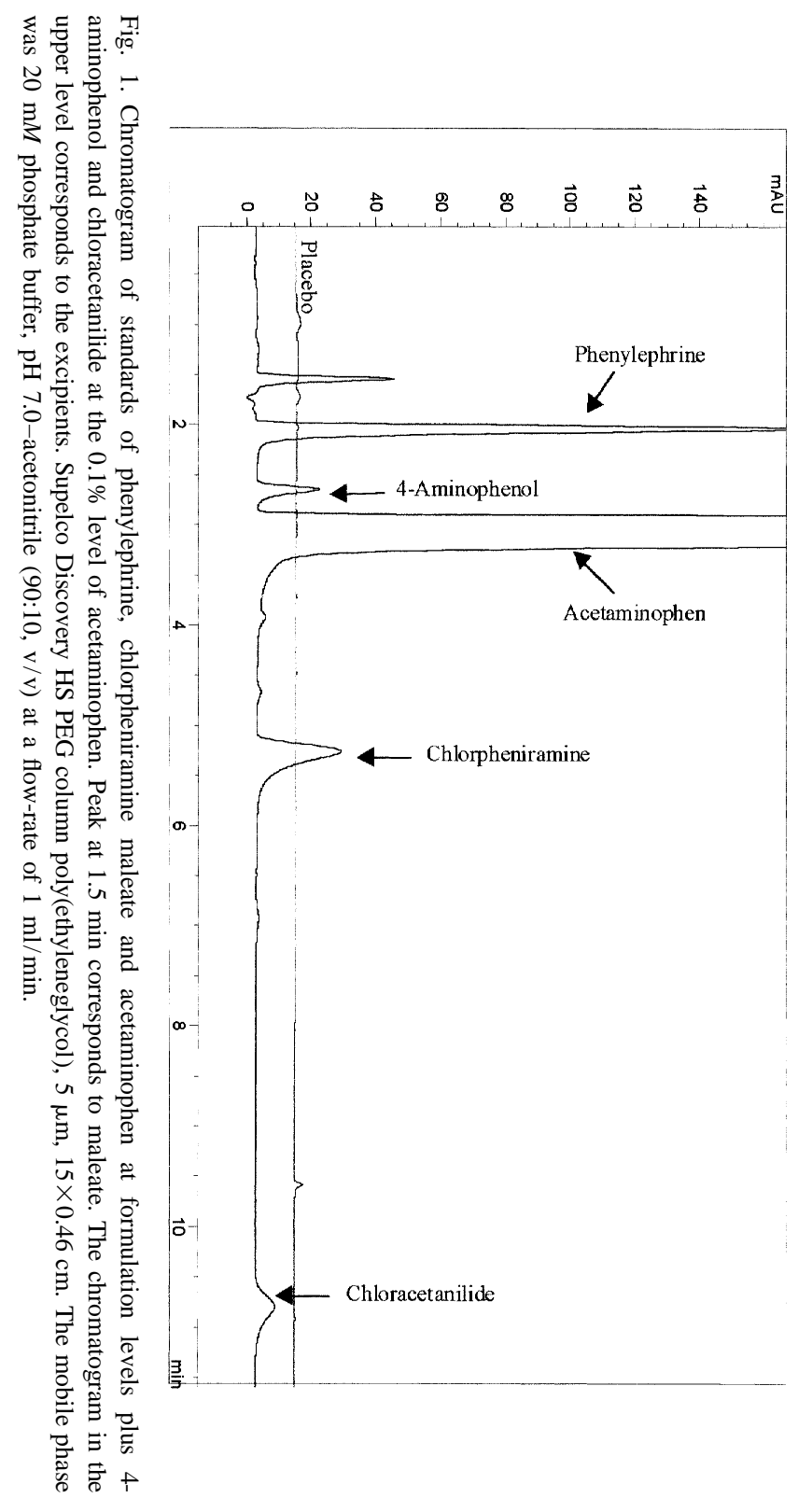

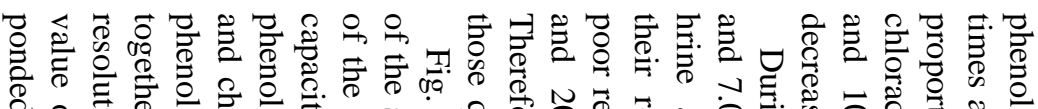

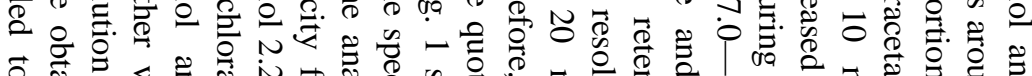

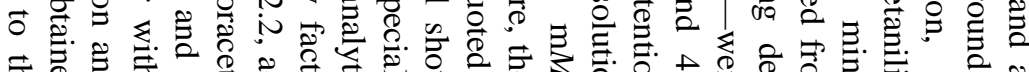

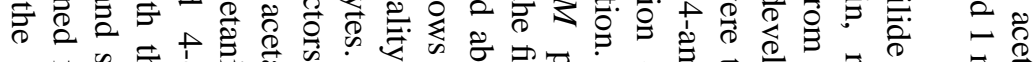

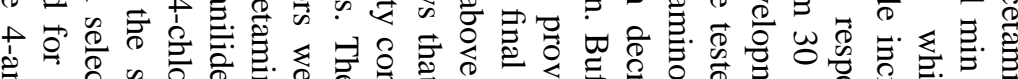

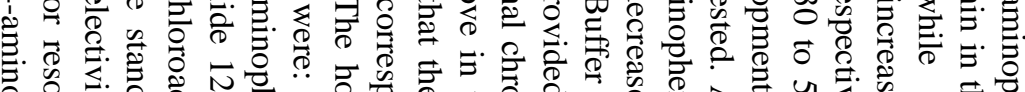

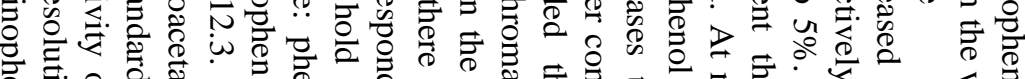

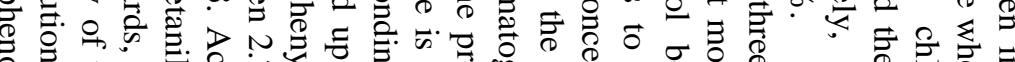

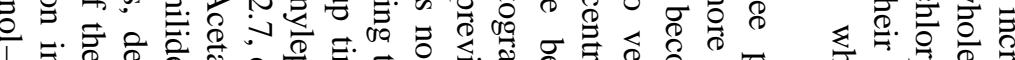

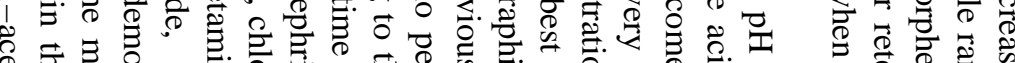

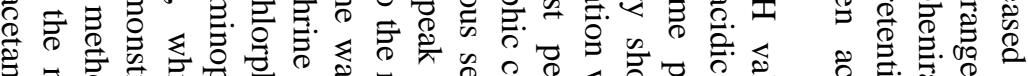

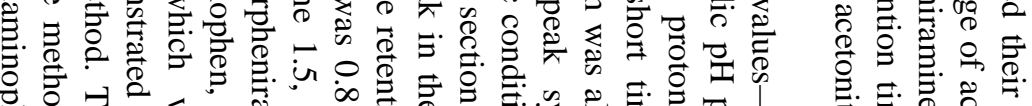

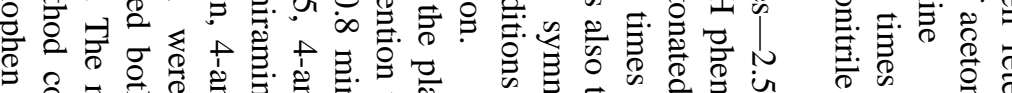

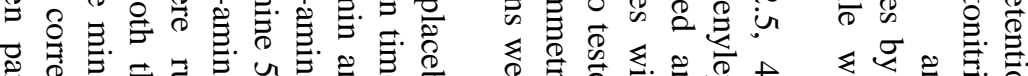

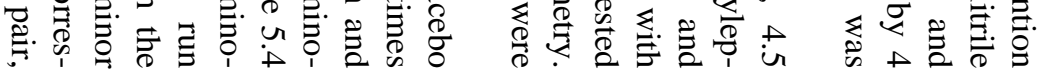

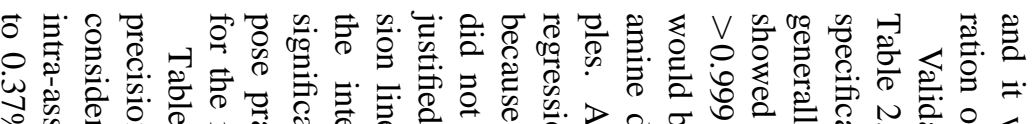

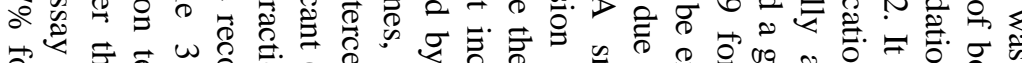

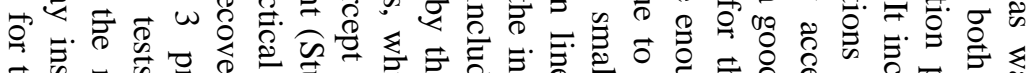

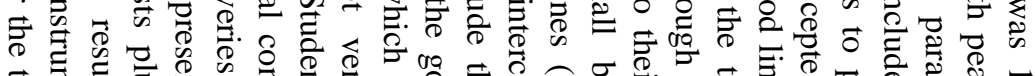
E

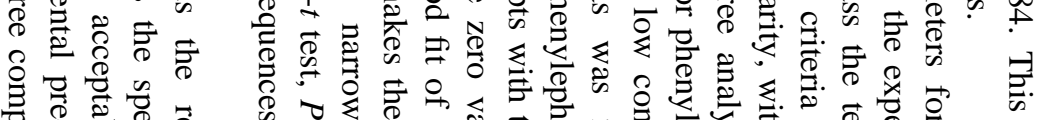

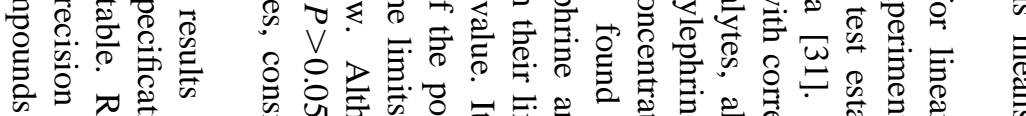

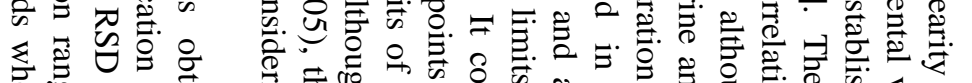
重学

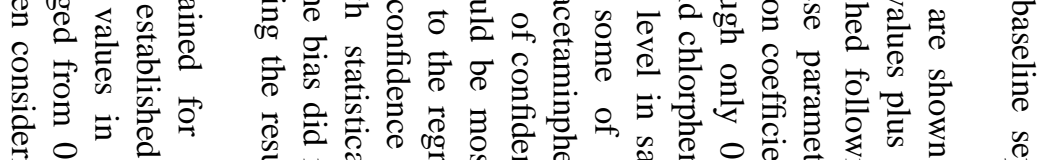

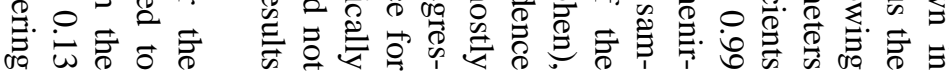


Table 2

Validation parameters for linearity

\begin{tabular}{|c|c|c|c|c|c|}
\hline \multicolumn{2}{|l|}{ Range $(\mathrm{mg} / \mathrm{ml})$} & Specification & $\begin{array}{l}\text { Phenylephrine } \\
0.15-0.25\end{array}$ & $\begin{array}{l}\text { Acetaminophen } \\
7.5-12.5\end{array}$ & $\begin{array}{l}\text { Chlorpheniramine } \\
0.06-0.10\end{array}$ \\
\hline Correlation coef & nt $(r)$ & $>0.999$ & 0.999 & 0.99998 & 0.999 \\
\hline $\begin{array}{l}\text { Linearity } \\
\text { test }\end{array}$ & $\begin{array}{l}\text { Response factor RSD }(\%) \\
\text { Slope } \\
\text { Confidence interval } \\
\text { Experimental } t\end{array}$ & $\begin{array}{l}<5 \\
0 \text { value not included } \\
t_{\text {exp }}>t_{\text {tab }}\end{array}$ & $\begin{array}{l}3.27 \\
18.5 \\
16.7-20.2 \\
33.1878\end{array}$ & $\begin{array}{l}0.89 \\
13.4 \\
13.2-13.5 \\
251.6554\end{array}$ & $\begin{array}{l}0.85 \\
8.1 \\
7.5-8.7 \\
42.7373\end{array}$ \\
\hline $\begin{array}{l}\text { Proportionality } \\
\text { test }\end{array}$ & $\begin{array}{l}\text { Intercept } \\
\text { Confidence interval } \\
\text { Experimental } t\end{array}$ & $\begin{array}{l}0 \text { value included } \\
t_{\exp }<t_{\mathrm{tab}}\end{array}$ & $\begin{array}{l}440.5 \\
263.0-648.1 \\
7.966\end{array}$ & $\begin{array}{l}73.0 \\
56.0-89.9 \\
13.6993\end{array}$ & $\begin{array}{l}30.4 \\
-30.3-91.1 \\
1.5944\end{array}$ \\
\hline
\end{tabular}

a single day, which means a very small variation due to instrumental causes, and from $0.80 \%$ to $2.91 \%$ when the areas of 2 different days were tested together. Chlorpheniramine did not pass the test, which means that calibration must be done daily, which is the usual practice. Chlorpheniramine's RSD for inter-day instrumental precision is an unusually high value, in comparison to the other RSD values.

For the intra-assay precision of the method RSDs for the three actives ranged from 0.93 to $1.91 \%$ on separate days and from 1.11 to $1.72 \%$ for inter-day precision. With these values and the intervals of acceptance established for the release of batches (95-105\%), one replicate of each sample ought to be measured for quantification.

Reproducibility was tested because the method will be employed in two different laboratories. As expected, the RSDs in each laboratory were similar to the method's RSDs and when considering results from both laboratories RSDs ranged from 1.83 to $2.16 \%$, which passes the specification to consider a low influence in the results due to the laboratory where the measurement was performed.

Recoveries were $98.8 \pm 0.4 \%$ for phenylephrine, $99.8 \pm 0.3 \%$ for acetaminophen and $100.2 \pm 0.8 \%$ for chlorpheniramine, which are not statistically significant ( $t$-test, $P<0.05)$.

The detection limits were $0.12,3$ and $0.05 \mu \mathrm{g} / \mathrm{ml}$ for phenylephrine, acetaminophen and chlorpheniramine, respectively, which corresponds to $0.06,0.03$, and $0.06 \%$ of the theoretical content of each active in the formulation.

The quantitation limit were $0.40,10$ and 0.16 $\mu \mathrm{g} / \mathrm{ml}$ for phenylephrine, acetaminophen and chlorpheniramine, respectively, which corresponds to $0.2 \%, 0.1 \%$, and $0.2 \%$ of the theoretical content of

Table 3

Validation parameters for sample precision in the quantitation level

\begin{tabular}{llllll}
\hline & & Specification & & & \\
\cline { 4 - 5 } & & & RSD (\%) & & \\
\cline { 4 - 5 } Instrumental & & & Phenylephrine & Acetaminophen & Chlorpheniramine \\
precision & Intra-day (day 1) & $<1.37 \%$ & 0.13 & 0.16 & 0.17 \\
& Intra-day (day 2) & & 0.21 & 0.37 & 0.26 \\
Method & Inter-day & $<1.94 \%$ & 1.11 & 0.80 & 2.91 \\
precision & Intra-day (day 1) & $<1.94 \%$ & 1.91 & 0.98 & 0.93 \\
& Intra-day (day 2) & & 1.38 & 1.29 & 1.85 \\
Reproducibility & Inter-day & $<2.74 \%$ & 1.72 & 1.04 & 1.43 \\
& Laboratory A & $<1.94 \%$ & 1.91 & 1.84 & 0.93 \\
& Laboratory B & & 1.42 & 1.83 & 1.87 \\
\hline
\end{tabular}


each active in the formulation. They were obtained by validating the method in these levels of concentration.

\section{Conclusion}

Polar reversed-phase materials can provide dramatically different separations compared to $\mathrm{C}_{18}$, yielding a more efficient analysis of samples that contain a wide range of polarities by reducing the analysis times and minimizing the necessity of gradient elution. This improvement is achieved by a combination of increased retention of polar species, which are retained away from the solvent front, and decreased retention of nonpolar compounds, which reduces the total analysis time.

An isocratic HPLC method has been developed for acetaminophen, phenylephrine and chlorpheniramine and related impurities measurement in capsules in less than $6 \mathrm{~min}$ of total run for the three active compounds and less than $12 \mathrm{~min}$ if the impurity chloracetanilide is included in the measurement. With this system long chromatographic analysis times (>20 min) and the employ of gradient elution or two different analysis can be avoided.

The method described in this study was found suitable to determine concentrations in the range $0.15-0.25 \mathrm{mg} / \mathrm{ml}$ for phenylephrine, $7.5-12.5 \mathrm{mg} /$ $\mathrm{ml}$ for acetaminophen and $0.06-0.10 \mathrm{mg} / \mathrm{ml}$ for chlorpheniramine, precisely and accurately, in agreement with the validation parameters obtained. Limits of quantitation for the three actives were $0.40,10$ and $0.16 \mu \mathrm{g} / \mathrm{ml}$ for phenylephrine, acetaminophen and chlorpheniramine, respectively. Therefore the method can be considered adequate for the intended purpose.

\section{References}

[1] A. Marín, E. García, A. García, C. Barbas, J. Pharm. Biomed. Anal. in press.

[2] T.H. King, C.K. Mann, T.J.Vickers, J. Pharm. Sci. 74 (1985) 443.

[3] R.E. Madsen, D.F. Magin, J. Pharm. Sci. 65 (1976) 924.

[4] F. De Fabrizio, J. Pharm. Sci. 69 (1980) 854.
[5] E. Mario, L. Meehan, J. Pharm. Sci. 59 (1970) 538.

[6] T.L. Sprieck, J. Pharm. Sci. 63 (1974) 591.

[7] A.M. Di Pietra, R. Gatti, V. Andrisano, V. Cavrini, J. Chromatogr. A 729 (1996) 355.

[8] X. Guo, W. Qian, C. Yang, X. Zhu, Se Pu 16 (1998) 164.

[9] C.Y. Ko, F.C. Marziani, C.A. Janicki, J. Pharm. Sci. 69 (1980) 1081.

[10] A.I. Gasco-Lopez, R. Izquierdo-Hornillos, A. Jimenez, J. Chromatogr. A 775 (1997) 179.

[11] T.A. Biemer, J. Chromatogr. 410 (1987) 206.

[12] L. Suntornsuk, Electrophoresis 22 (2001) 139.

[13] S. Ji, Y. Chai, Y. Wu, D. Liang, Z. Xu, X. Li, Yaowu Fenxi Zazhi 18 (1998) 170.

[14] H. Nishi, T. Fukuyama, M. Matsuo, S. Terabe, J. Chromatogr. 498 (1990) 313.

[15] V. Das Gupta, A.R. Heble, J. Pharm. Sci. 73 (1984) 1553.

[16] G. Indrayanto, A. Sunarto, Y. Adriani, J. Pharm. Biomed. Anal. 13 (1995) 1555.

[17] X. Zhao, B. Tan, H. Zhang, Huaxi Yaoxue Zazhi 13 (1998) 271.

[18] D.J. Krieger, J. Assoc. Off. Anal. Chem. 67 (1984) 339.

[19] MAC-MOD. Zorbax HPLC columns. Application Briefs, The analysis of commercial over the counter cough and cold remedies using StableBond ${ }^{\circledR}$ Cyano (SB-CN) columns [web page]. Available at www.mac-mod.com/ab/96101-ab.html.

[20] Phenomenex, MAXSIL HPLC columns [web page]. Available at http://www.phenomenex.com/Phen/Doc/zhmax.pdf.

[21] Agilent Technologies, Zorbax HPLC method development hints [web page]. Available at http://www.selbybiolab.com.au/whats\%20new/Zorbax\%20April\%20 May\%20newsletter/Zorbax.html.

[22] MAC-MOD. HPLC column companion, Section 11: what can you do to improve the peak shape of bases? [web page]. Available at www.mac-mod.com/cc/cc-11-bases.html.

[23] Phenomenex, SYNERGI HPLC column. New HPLC columns and automated column selectors for fast HPLC method development [web page]. Available at www.phenomenex.com/Phen/Doc/zhpolr.pdf.

[24] ICH: Q2B Analytical validation methodology, ICH Harmonised Tripartite Guideline, 1996, Step 4.

[25] G.L. Long, J.D. Winefordner, Anal. Chem. 55 (1983) 712.

[26] Numerical [web page]. Available at www.sunderland.ac.uk/ $\sim \mathrm{hs} 0 \mathrm{dad} / \mathrm{qm} / \mathrm{cti} 4 /$ numerica.htm.

[27] The Pharmaceutical Society of Great Britain, in: The Pharmaceutical Codex, 11th edition, The Pharmaceutical Press, London, 1979, p. 695.

[28] The Merck Index. An Encyclopedia of Chemicals, Drugs, and Biomedicals. 13th Edition. Merck Research Laboratories. Division of Merck, Whitehouse Station, NJ, 2001.

[29] Clarke's Isolation and Identification of Drugs, 2nd edition, The Pharmaceutical Press, London, 1986.

[30] Chemistry 130B [web page]. Available at www.chem.ucla.edu/ harding/130B_w99_final_key.html.

[31] G.P. Carr, J.C. Wahlich, J. Pharm. Biomed. Anal. 8 (1990) 613. 